OPEN ACCESS

Edited by: Kim Ceulemans,

TBS Business School, France

Reviewed by:

Clemens Mader

Swiss Federal Laboratories for

Materials Science and

Technology, Switzerland Antje Disterheft

New University of Lisbon, Portugal

${ }^{*}$ Correspondence: Stephen Sterling stephen.sterling@plymouth.ac.uk

Specialty section

This article was submitted to

Sustainable Organizations,

a section of the journal

Frontiers in Sustainability

Received: 19 July 2021 Accepted: 03 December 2021 Published: 23 December 2021

Citation:

Sterling S (2021) Concern, Conception, and Consequence: Re-thinking the Paradigm of Higher Education in Dangerous Times.

Front. Sustain. 2:743806 doi: 10.3389/frsus.2021.743806

\section{Concern, Conception, and Consequence: Re-thinking the Paradigm of Higher Education in Dangerous Times}

\author{
Stephen Sterling* \\ Centre for Sustainable Futures, Sustainable Earth Institute, University of Plymouth, Plymouth, United Kingdom
}

Discussion of the role of universities in relation to broad issues of sustainability has been current for some decades, although predominantly at the margins of debate and policy. Yet a recent rapid rise of concern-catalyzed by mounting evidence of climate crisis, biodiversity loss, pandemic disease and further systemic issues -is focusing renewed attention on the adequacy of the response of higher education to unprecedented times of urgency, uncertainty and threat. Whilst it is now widely acknowledged that the fate of the planet and of humanity hangs in the balance, there still remains an astonishing disconnect between pressing signs of global change, and the relatively closed world of higher education. A trend toward greening universities' operations is positive, but fails to engage or galvanize the cultural and value shift toward a holistic and ecological zeitgeist that is now necessary to generate widespread institutional systemic change. This paper delves into deep causal factors that have historically impeded the ability of universities to respond fully and effectively to present and probable future realities, pointing to the foundations of Western thought such as reductionism, objectivism, dualism, individualism, anthropocentrism, rationalism, instrumentalism and technocentrism that shape mainstream education policy and practice, overlain and reinforced in more recent times by neo-liberal conceptions of the purpose of universities in a modern economy. It is argued that these elements of our culturally shared worldview constrain our ability to perceive and respond deeply, fully and wisely to the global predicament, but also maintain destructive patterns of development. Whilst there is increasing acceptance that education must "transform" in order to-in turn-be transformative in effect, there is less clarity about the guiding assumptions and ideas that inform mainstream policy and practice, and about the philosophic value bases that can facilitate transformative educational thinking, policy and practice. A framework of three broad and complementary components of paradigm-Concern, Conception, and Consequence - is employed to outline the shape of the systemic paradigmatic shift that universities need to urgently navigate in order to maximize their ability to respond fully to contemporary socio-economic and ecological conditions and trajectories.

Keywords: higher education, sustainability, paradigm, system failure, ecological worldview, systemisism, transformative learning, regenerative education 


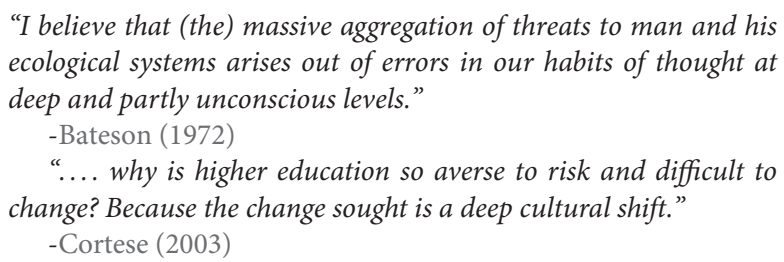

"I believe that (the) massive aggregation of threats to man and his ecological systems arises out of errors in our habits of thought at deep and partly unconscious levels."

-Bateson (1972)

".... why is higher education so averse to risk and difficult to change? Because the change sought is a deep cultural shift."

-Cortese (2003)

\section{INTRODUCTION}

The paramount challenge of our times is to secure a liveable future for humanity and the natural world. Now is the epochal moment in human history-whereby the net impact that universities have in the next few years will either help assure the future, or contribute to social, economic and environmental collapse sometime this century (Figueres and Carnac, 2020; Weyhenmeyer and Steffen, 2020).

There is mounting authoritative evidence of deep systemic global crises that show every sign of radically diminishing the quality of life and prospects of present and future generations, and at worst, may harbinger the end of human tenure on the planet sometime this century. The whole world is now living in dangerous times. A state of socio-ecological sustainability or maintained comprehensive well-being requires a prior state of socio-ecological security or stability, and this in turn, requires a prior state of socio-ecological survival. Yet we cannot be sure that any of these nesting conditions will be manifested into the future.

In her book on our "dark age" and the possibility of avoiding cultural and social collapse through renewal, Jacobs (2005) underlies the crucial role of education:

A vigorous culture capable of making corrective, stabilizing changes depends heavily on its educated people, and especially on their critical capacities and depth of understanding.

But time is short. Given this context, the overriding questions are these:

- how can universities urgently transform their ethos, policies and practices to function in service of the survival and wellbeing of humanity and the planet, at a time of growing instability and existential threat?

- how do we avoid universities adopting a reformist position in response to the multiple global crises, rather than the transformist response that the crises require?

- how can second and third- order learning within entire university systems be set in train that will engender their ability to make a critical contribution to human, biotic and planetary survival and flourishing?

These pressing questions center on what I have termed "response-ability" (Sterling and Martin, 2019). This refers to the ability and capacity of educational systems and institutions to respond markedly and proportionately to a precarious socioeconomic and ecological mix which has been brewing for decades and which now threatens our shared future as well as that of our fellow species in the other-than-human world.

In this paper, I argue that education bears some historic and current responsibility for our current state of global unsustainability, that this largely arises from its perpetuation of the dominant Western modernist paradigm or worldview, and that this now needs to be transformed urgently toward systemisism, that is, a holistic, relational or ecological basis. As our actions and practice arise from the way we view the world, it is now essential that-as far as possible-we exercise critical reflexivity. This involves recognizing and "examining our own assumptions, decisions, actions, interactions, and the assumptions underpinning organizational policies and practices and the intended and potentially unintended impact" (Cunliffe, 2016). Further, such reflexivity is "is about having 'a heart', it is not a technique but a way of being in relation with others that brings with it moral and ethical considerations" (Cunliffe, 2016).

At a deep level this means achieving "epistemic consciousness" or worldview awareness at individual, societal and institutional scales (Bawden, 1987). Our multiple predicaments are not simply external but arise, are manifested, and maintained at root from the limited and maladapted way we collectively view the world (Laszlo, 1989; Meadows et al., 1992; Capra and Luisi, 2014). More than 30 years ago, Maturana and Varela (1987) wrote:

...the chance of surviving with dignity on this planet hinges on the acquisition of a new mind. This new mind must be wrought, among other things, from a radically different epistemology which will inform relevant actions.

Therefore, it is only by consciously and determinedly changing our worldview at this critical juncture of the human story that we can precipitate wise and sufficient action to secure the future.

Below, a thought-model outlining three transformative shifts toward a postmodern ecological paradigm in higher education is proposed, encapsulated in three component parts, Concern, Conception and Consequence.

The paper does not look at the details of educational policy and practice that an ecological paradigm gives rise to (which I and others have covered extensively, for example Sterling, 2012, 2013; Assadourian, 2017; Armon et al., 2019; Wright and Hill, 2021, and which are elaborated in other papers in this Research Topic). Neither does the paper attempt to do much more than touch on the process of transformational institutional change as this is a whole further inquiry. Rather, it focuses on the essence of the shift that contemporary socio-ecological conditions now require.

My method has developed from very long involvement and research in education, particularly with respect to the challenge of orienting educational systems toward embracing sustainability fully. From this experience-including thorough engagement in related discourse over this time-I have developed an approach which is partly based on empirical observation, and partly based on deep reflection, and on philosophical and normative reasoning. In this approach I have been influenced by deliberative inquiry and by appreciative inquiry. But as a relational thinker, I was impressed years ago by Gregory Bateson's distinction between deductive and inductive thinking on the one hand, and abductive thinking on the other. Abductive reasoning is a way of developing new ideas from incomplete evidence and suggesting explanations and ways forward. For Bateson (1980), this approach led to his famous phrase regarding "the pattern that connects" phenomena. Indeed, the attempt to "find pattern" 
is an appropriate description of the analysis, synthesis and development of the argument and associated models that are put forward here. They are "thought models," and they are hypothetical and essentially propositional.

They are offered to help those work in higher education think through the essential problem which spurred this Research Topic, whereby the Frontiers in Sustainability Call for Papers on the "transformational role of academic institutions" underlined the need to re-imagine the societal role and responsibility of Universities. The Call notes that this will bear on "deep and rich epistemic roots". As the paper offers propositional arguments, it is up to the reader to weigh their validity in relation to their own experience, and more importantly, how far they are useful and helpful.

Whilst the models were first developed in my doctoral thesis (Sterling, 2003), in this paper, the implications of the dimensions of paradigm, of levels of knowing, and of aspects of educational culture are brought together and specifically elaborated and discussed in relation to higher education - with a focus on the possibility of systemic institutional change in the context of renewed and urgent debate on this issue.

\section{TRANSFORMING EDUCATIONAL SYSTEMS}

The transformation of education and educational systems is receiving increasing and necessary attention in the growing debate on the role of education in relation to securing the future.

UNESCO has set up an International Commission on the Futures of Education (ICFE) to "rethink education in a world of increasing complexity, uncertainty, inequalities, risks and possibilities" (ICFE, 2021). Their interim report of March 2021 (ICFE, 2021) states that:

\begin{abstract}
The ways that the planet has been transformed by human activity have profound implications for the purposes of education and organization of learning in the future. For too long, education has been based on a growth-focused modernist development paradigm. Moving toward a new ecologically oriented understanding of humanity that integrates our ways of relating to Earth, requires an urgent rethinking of education in the 2050 horizon.
\end{abstract}

This is an eloquent and promising statement, yet curiously, this well-intentioned document is very light on exploration of the cultural and paradigmatic norms that inform current thinking and practice, and on the ecologically based alternatives that would help the "urgent rethinking" that it advocates. In the absence of a convincing critique, and of a robust case for an alternative pathway, there is a real danger that "business as usual" will prevail.

UNESCO is also the agency behind the current international policy document on Education for Sustainable Development (ESD). This Roadmap: ESD for 2030 (UNESCO, 2020) strongly endorses global progress to date on Education for Sustainable Development (ESD), and reflects both urgency and the need for transformative change in educational systems if the Sustainable
Development Goals (SDGs) are to be met. Resonant with the International Commission on the Futures of Education (above), the document states that "Education must transform itself" (UNESCO, 2020).

Earlier, in 2016, UNESCO devoted its annual Global Education Monitoring (GEM) report to Education for People and Planet. Subtitled "Creating sustainable futures for all," a key message of the report was that, "education needs a major transformation to fulfill (its) potential and meet the current challenges facing humanity and the planet" (UNESCO, 2016).

The rhetoric is strong and well-expressed in these documents, but there is a deep problem which has handicapped UNESCO's work for years. That is, its policy papers never adequately explore why the values and assumptions that shape mainstream educational policy are as they are (Silova et al., 2018): Why in practice sustainability education is-so often-not recognized or interpreted with narrow focus. Or otherwise rendered "safe."

Another issue is UNESCO's continuing reference (as reflected in their "Roadmap") to the need "integrate" sustainability or ESD into education. As I have argued (Sterling, 2004):

The effect of patterns of unsustainability on our current and future prospects is so pressing that the response of higher education should not be predicated only on the "integration of sustainability" into higher education, because this invites a limited, adaptive, response. Rather, I will argue, we need to see the relationship the other way round-that is, the necessary transformation of higher education toward the integrative and more whole state implied by a systemic view of sustainability in education and society, however difficult this may be to realize.

Now, years later, the case for such re-thinking and re-making of educational systems is even more urgent.

The two current and influential initiatives-the International Commission on the Futures of Education, and UNESCO's Roadmap-are of course important and very welcome. They indicate an incipient second-order learning in the international education community, comprising recognition that first-order "business as usual" education that has been dominant for decades is no longer viable, tenable or ethically defensible. Yet, by concentrating attention on Policy and Practice, and largely bypassing Purpose and Paradigm, the UNESCO initiatives' case for the substantial transformation of educational systems-and thereby its prospect in terms of impact-are seriously weakened.

Rather, we need to attempt to consciously "step outside the usual frame of reference" (Ison and Russell, 2000) and exercise individual and collective reflexivity as an "ongoing process of inquiry" (Moore et al., 2018) in order to see and acknowledge the operative power of the dominant paradigm. As I have written previously (Sterling, 2013):

Higher education still largely reflects the Western intellectual legacy from whence it came, rooted in the memes of the prevalent education epistemology-reductionism, objectivism, materialism, dualism and determinism underlain by a mechanistic metaphor-refracted from the wider cultural milieu and exerting an influence on purpose, policy and provision, as well as in educational discourse. 
These habits of thought reside in the subterranean layers of the university culture and manifest in the educational landscape above the surface: hierarchical governance, single disciplines, separate departments, abstract and bounded knowledge, belief in value-free knowing and a reluctance to engage with ethical matters in the curriculum, privileging of cognitive/intellectual and technical knowing over affective and practical knowing, prevalence of instrumental rationality, transmissive pedagogy, linearly arranged learning spaces, valuing of analysis over synthesis and an emphasis on first-order or maintenance learning which leaves basic values unexamined and unchanged both individually and institutionally.

The writer on system designs of education, Banathy (1991), argues that the dominant paradigm cannot, "possibly cope with the complexity, mutual causality, purpose, intention, uncertainty, ambiguity, and ever accelerating dynamic changes that characterize our systems and larger society environment." Some 30 years later, the veracity of this view is becoming ever more evident. My own research led me to posit a transformative paradigm of sustainable education (Sterling, 2001, 2009) proposed as a cultural shift built on individual and institutional learning informed by ecological and systemic thinking and values. There is therefore a most important distinction between "sustainability education" which often represents a change in pedagogy and curricula, and "sustainable education" which represents a transition of educational culture as a whole. The latter promises a liberatory escape from the bedrocks of the prevalent education episteme (reductionism, objectivism, materialism, and dualism) overlain by the impoverishing effect of neo-liberal thinking, and maintained by a collective psyche that exerts an unexamined influence over purpose, policy, and provision and associated educational discourse.

These constraining influences combine to effect a kind of inertia in educational systems. This can be illuminated by the ideas of system failure. This in turn further evokes questions of worldview/paradigm and the promise of transformative learning within educational systems.

\section{SYSTEM FAILURE, LEARNING LEVELS AND WORLDVIEW}

Historically, high level international documents and reportsfrom the UN Conference on the Human Environment 1972 to the present-have repeatedly endorsed education's role vis-à-vis sustainability and ensuring well-being. Yet at both national and institutional levels the ensuing debate has largely taken place on the margins of mainstream discourse and educational policywith little tangible and substantial effect on either over the last two decades. By and large, higher education remains maladapted to the global conditions that are now determining the future (Assadourian, 2017). Our learning system is not itself learning (Sterling, 2009, 2017).

However, in very recent years - galvanized by incontrovertible evidence of multiple global crises, and challenged by the UN Sustainable Development Goals (SDGs) - the scale of change required is beginning to be recognized in higher education, at least by some of the world's more progressive universities and networks although it is mostly affecting research agendas rather than teaching and curricula. However, the discourse around higher education and the SDGs tends to center on process and implementation, rather than adopt a critically reflexive stance toward the assumptions and norms that frame the SDGs (Wulf, 2020; Sterling, 2021; Wals, 2021). Yet the SDGs have led to a significant wave of interest, response and innovation across the higher education sector (see for example https://blogs.upm.es/education4sdg/?mc_cid= a1c356dbb6\&mc_eid=127096ab79) and https://www.iau-hesd. net/contenu/4648-iau-global-cluster-hesd.html) and some of this work is exceptional.

But this is a late and yet partial dawn: education's part in helping secure the possibility of a more sustainable future has for years been predominantly the domain of enthusiasts and the newly concerned-among them of course, vocal students who currently recognize in increasing numbers that their future is very much at stake (see for example https://fridaysforfuture. org/ and https://www.teachthefuture.uk/). Meanwhile however, as David Orr suggests, most senior managements, "calmly regard the transition ahead as fine-tuning of more of the same" (Orr, 2016). This limited response represents first-order learning, and it falls well short of the "deep cultural shift" (to use Cortese's words, above) (2003) that is now urgently needed.

We can invoke here the notion of "system failure." According to Peters (1999) failure can be considered to be of four types: objectives not met; undesirable side effects; designed failures; and, inappropriate objectives. Criticism of education-particularly in political debate-often centers on the first meaning, but given the incontrovertible imperative of educating for socioecological survival and well-being, education largely "fails" in terms of the other aspects of system failure: undesirable sideeffects include widespread ecological/sustainability illiteracy and its consequences, many participants and actors in the system are dis-engaged or stressed through the design of the system, and most seriously, the purposes or objectives of education whether at national or institutional level largely fail to take into full account the urgency of global challenges. Jacobs (2005) critiques a narrowing of purposive horizons in universities from the midtwentieth century onwards-from embodying education per se toward what she terms "credentialling" in the service of the economy. At a deeper level, Orr (2021) points out that, "The planetary crisis cannot be attributed to the uneducated, but rather to the highly degreed.... The important problems are those of education not those in education."

I argue (Sterling, 2004) that the root of this system failure is our shared worldview or social paradigm-anthropocentric, materialist, dualist, positivist, reductionist, objectivist, rationalist, individualist, to name some key complementary characteristics. Here, I follow Gregory Bateson's iconoclastic critique of the Western mindset as possessing "errors in our habits of thought at deep and partly unconscious levels," an "epistemological error" characterized by both a perception of and belief in separateness which, while it works to a degree, is ultimately destructive (Bateson, 1972). Our dominant mechanistic worldview or epistemology (McGilchrist, 2009; Capra and Luisi, 2014; 
Smitsman et al., 2019) — held partly at non-conscious levels-has given rise to and maintains an unsustainable and degenerative relationship with the ecosphere, and this same epistemology is dominant in and perpetuated by Western educational systems. The deleterious consequences of this worldview have been compounded by the ideologically oriented neoliberal economic paradigm that has dominated political, social and economic policy since the late 1970's and which has ushered in, "not only the greatest inequality and ecological destruction humankind has ever known, but also failed to promote psychosocial well-being" (Costanza et al., 2020).

As education is a subsystem of society, then by an inexorable logic, education has largely been part of the overall system failure in the relationship between society and the ecosphere (Silova et al., 2018). Also see extensive discussion at https:// greattransition.org/gti-forum/pedagogy-transition.

This presents a profound paradox and irony: the agency that is charged with the provision of education and learning in service of the future-i.e., the education system and its component parts including higher education - is part of the unsustainability problem it needs to address. The education system itself might be characterized as a "wicked problem." Yet education is seen as a critically important part of building a safe future (UNESCO, 2020; ICFE, 2021).

Whilst the term "system failure" is not employed by UNESCO, the emphasis on the need for fundamental change in educational systems is now strong. This is central to its recent and current policy documents, and specifically its current "roadmap" to address the SDGs by 2030 through education:

To ensure individuals are able to understand sustainability challenges, to be aware of their relevance to the surrounding realities, and take action for change, to trigger structural transformations in today's economic and social systems by promoting alternative values and contextualized methods, to address the new opportunities and risks on sustainable development posed by emerging technologies, education needs to transform itself (UNESCO, 2020).

In this paper, I follow systems thinking practice by offering a holistic analysis and model at a high level of abstractiona "big picture" method which helps deal with complexity by providing "a wider context for thinking processes" (Chapman, 2002). Chapman argues that it is the lack of such holistic perspectives that contribute to systems failure. Consequently, in this paper, and through offering a number of "thought models," I offer holistic/systemic perspectives that I argue are necessary if education is to "transform itself" as UNESCO makes clear is now urgent.

Gregory Bateson (1972) made a seminal distinction between different levels of learning, which has had a profound effect on learning theory, and can help us move beyond repeated system failure in education. The language of transformation directly implies learning within the system such that the system itself is changed. This is second-order learning, and beyond that, thirdorder learning (epistemic/transformative learning) can occur. Ison and Russell (2000) note that:
In order to achieve (this) it is necessary to step outside the usual frame of reference and take a meta-perspective. First-order change is change within the system, or more of the same (my italics).

Rather, we need to unlock deep systemic change, and thereby unlock the potential of higher education toward securing a more sustainable world-and rapidly. Arguably, as the systemic crises bite, our shared "epistemological error" of separation is becoming ever more apparent (even if it is not labeled as such). The realization of profound human and biotic/biospheric interdependence is breaking the illusion of separation and disassociation and giving rise to "a relational, ecological or participative consciousness appropriate to the deeply interconnected world that we have created" (Sterling, 2007). The emergence of the ecological worldview may be seen as evidence of a deep learning process of social change including unlearning (Moore et al., 2018).

This process now appears to be accelerating toward a kind of cultural zeitgeist (Dash, 2019) which may, or may not, prevail. It entails a shift of emphasis from relationships largely based on separation, linearity, control, manipulation, growth and excessive competition toward those based on context, holism, circularity, participation, appreciation, collaboration, limits, equity, peace and social and ecological justice. It is otherwise referred to as "participative" (Reason and Bradbury, 2001) "co-evolutionary" (Norgaard, 1994), and as the "postmodern ecological worldview" (Zweers, 2000). Alternatively, it is described as a Gaian or "living systems" (Elgin, 1994) view of the world, which accords with many non-Western indigenous perspectives and longheld traditions (Smitsman et al., 2019). Fundamentally, it is challenging us to rediscover our humanity and our place on the planet whilst there is still time.

In this emerging context, the appropriate and necessary response is that higher education institutions move toward becoming-primarily_systemic learning organizations whereby transformative and iterative learning occurs within education systems and amongst policymakers and practitioners as well as students. The university then becomes over time an adaptive, innovating institution engaged in a continual co-evolutionary learning process with community and society, shifting from a "delivery" role to one of critical engagement (Fear et al., 2006; Martin and Sterling, 2019).

Banathy (1991) suggests this signals a change of purpose and role from education focusing on maintaining the existing state and operating as a somewhat closed system, toward helping reshape society, "through co-evolutionary interactions, as a futurecreating, innovative and open system."

This maybe said to be a transformative shift of essence from reductionism toward systemisism [relationism, or relationality (Lange et al., 2021)] as a fundamental principle of educational thinking, policy and practice. Systemisism is a belief or view that a systems view of the world is an appropriate metaphor for understanding the world, our interrelationship with it and acting in it. This is a "fundamental change of metaphors from seeing the world as a machine, to understanding it as a network" (Capra and Luisi, 2014). It is a shift which is now gaining much 
more attention in discourse, and it marks the emergence of the ecological or living systems view of the world.

\section{FINDING THE KEY}

My professional work as an educator began over 40 years ago-with an early conviction that education and learning had a critical role in addressing (what were then seen solely as) environmental issues.

In all those years, I've been more or less perplexed as to why education has not responded proportionately to the great realworld issues that would affect the lives of those who were being educated. Why, as Lautensach (2020), there has been and remains a "chronic consensual blindness and inertia" in higher education. But I've also been questioning how far, and why, education has too often been more of a contributory than a remedial influence in the generation and growth of these issues-in part, responsible for the global conditions of unsustainability that universities are now being required to address. My work culminated in a doctoral thesis (quite late in my career) on whole systems thinking, paradigm change and education (Sterling, 2003) which to some extent informs this paper.

This research over some decades has sought to develop insight into understanding why mainstream educational discourse, policy and practice manifests as it does, and into its adequacy for our times of existential threat. Secondly, I have explored the alternative bases on which education that is commensurate with the current profound need for cultural change toward a safe future can be realized.

The deeper level which has been central to my work has been that of paradigm. As systems thinking leader Donella Meadows writes (1999) the most powerful lever of change is, "The mindset or paradigm out of which the system-its goals, power structure, rules, its culture-arises." Paradigm refers to the underlying set of perceptions, assumptions, values, and concepts which have internal consistency - that at individual level may be seen as equivalent with worldview, and similarly at societal level, with its prevailing cultural belief and value system (Capra and Luisi, 2014). In educational terms, a dominant paradigm affects how educational realities-purpose, policy, practice-are viewed and, therefore also, how they are shaped and manifested.

Insight here provides a key to unlocking answers to fundamental questions such as why education discourse is framed in a particular way, why certain values and practices are upheld and others discounted, and why philosophical and practical alternatives are marginalized even when evidence is in their favor: Why mainstream thinking, policies and modi operandi prevailing in many universities constitute resilient systems which are resistant to the significant change that the sustainable futures agenda requires. And, importantly, why universities-in the business of teaching and learningare not, with few exceptions, themselves systemic learning organizations. Examination and reflection at this fundamental level of paradigm is also essential to the articulation of viable, tenable and convincing alternatives that can challenge and transcend outmoded "business as usual" frameworks that still hold powerful sway and within which most discourse, policy and practice lies (Laszlo, 2019; Wright and Hill, 2021).

\section{THE TRIANG MODEL}

In this paper, I propose an essentially simple yet potent triadic model intended to help those involved in higher education achieve some critical reflexivity with regard to the three fundamental shifts that are entailed in realignment. That is, moving from the dominant education paradigm (characterized by mechanistic control-oriented thinking, reductionism, instrumentalism, managerialism, standardization, the global testing culture (Smith, 2016) and neo-liberal conception and purpose) toward a more systemic, ecological, dynamic learning paradigm commensurate with - and necessary to work effectively within - current global conditions of uncertainty, complexity, emergence and threat.

It is important to note that it is not a matter of superseding the old (yet still current) paradigm - this is neither possible nor desirable. Rather, the holistic paradigm needs to be seen as subsuming the mechanistic paradigm (as in the relation between Whole and Part), whereby the latter's methods become tools for conscious use where appropriate, rather than remain unexamined habits of thought and practice. This accords with Wilber's evolutionary view of paradigm change, where a larger and new framing arises from a growing realization of the mismatch (or "incoherence" Bohm, 1992) between conventional and long-accepted ways of seeing/knowing/doing and pressing external realities (Wilber, 1996).

Years of shared practical experience have taught me that making this shift is extraordinarily difficult, particularly in institutions. As Homer-Dixon (2006) suggests, "we often invest enormous mental energy to maintain a perspective on the world that's at variance with reality." So the challenge for those who are or might become change agents cannot be underestimated (Moore et al., 2018). There seems to be an element of lock-in and non-learning operating here, even as the encompassing conditions of complexity, systemicity, uncertainty and unsustainability become ever more evident in wider society (most recently evidenced by the Covid pandemic). At individual level, the maintenance of deep-seated worldviews tends to prevail despite evidence that they may no longer be adequate for changed conditions. It may be that Chapman's view (2002, p. 14) is true of many, who, he suggests:

... will not change their mode of thinking or operating within the world until their existing modes are proved beyond doubt, through direct experience, to be failing.

Whilst Bawden and Allenby (2017) worry that:

...it is entirely possible that in our slavish, non-reflexive commitment to the objectivist positivist epistemologies, atomist reductionist ontologies and individualistic neoliberal axiologies of the so-called Enlightenment epoch, we have fallen into an epistemic trap from which we are incapable of escape. 
Yet current and worsening global trajectories make worldview change necessary and urgent. There are signs that it is taking effect. Metaphorical cracks are appearing as "business as usual" norms appear increasingly untenable in the current tightening conditions of multiple local and global crises. It may not be a cultural epiphany, but it seems clear that a late awakening and movement is underway (see for example https://www.eauc.org. uk/climate_commission).

In education, the change involves second- and perhaps thirdorder learning within university communities where increasing numbers of academics, professional staffs and students are seeking change, aware that the future is under threat. Meadows (1999) suggests that whilst paradigm change is the most powerful tool in whole system change, it is the hardest shift to achieve - and yet at individual level "it can happen in a millisecond. All it takes is click in the mind... a new way of seeing."

The rest of the paper is an attempt to outline some of the grounding and broad implications of such systemic change.

A framework which can help illuminate and help realize this shift is (what I have named in this paper) the 'Triang Model' (triangular). It is a device that - through different interpretations - helps clarify the nature of paradigm. I first developed this model through my doctoral research (Sterling, 2003) http://www. bath.ac.uk/cree/sterling/sterlingthesis.pdf and have worked on its implications and possible utility since. Whilst the theory is elaborated in depth in Sterling (2007) and has been taken up by others (see for example Cook, 2019), this paper represents the first attempt to adapt the model to the context of the challenge to universities to adapt rapidly to the new conditions of global crisis and instability. I maintain that it may help deep recognition of and reflection on paradigm.

Before going further, note that I am using the term "epistemology" in the broad sense reflected in Bateson and Bateson's (1988) definition of epistemology being about "the necessary limits and other characteristics of the processes of knowing, thinking and deciding".. I use "epistemology" here then, to mean or describe the operative way of knowing, thinking and valuing that frames people's perception of and interaction with the world - their episteme - rather than the narrower sense normally employed in research. Hence, Milbrath (1994) describes worldviews as "epistemological structures for interpreting reality that ground their picture of "reality" in their own construction." In brief, and to underline the point, the operational epistemology or "knowledge system" of the dominant techno-scientific worldview which influences us all, is essentially positivist, dualist, objectivist and reductionist, and based upon the root metaphor of mechanism.

The Triang Model can be seen as sets of three fundamental and interrelated dimensions (represented in Table 1). These can be interpreted variously. So reading down and across simultaneously, the interpretations may be seen as different expressions of (any) paradigm operating at individual or group level.

For the purposes of this paper, and with respect to universities, the triad can be interpreted or translated as the domains of Concern, Conception and Consequence, suggested here as
TABLE 1 | Triang model: dimensions and interpretations of paradigm.

\begin{tabular}{lll}
\hline Seeing domain & Knowing domain & Doing domain \\
\hline Perception & Conception & Practice \\
Affective dimension & Cognitive dimension & Intentional (design) dimension \\
Epistemology (+axiology) & Ontology & Methodology \\
Ethos & Eidos & Praxis \\
Concern (purpose) & Conception (operation) & Consequence (effect/impact)
\end{tabular}

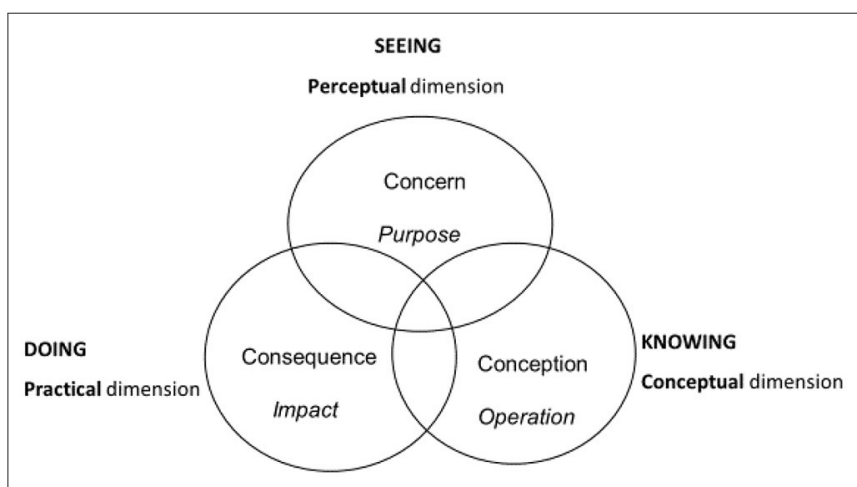

FIGURE 1 | Dimensions of paradigm - key domains in relation to the university.

representing the essential architecture or pillars of the university's Purpose, Operation and Effect (Table 1; Figure 1).

Before elaborating how this apparently minimal model can help us chart a course toward a more holistic and ecological educational paradigm, it is necessary to review the fundamental influence of paradigm.

\section{THE POWER OF PARADIGM ON LEVELS OF KNOWING}

The prevailing educational paradigm may be seen as a subsystem of the dominant cultural worldview which it reflects and within which it is embedded. This raises an important question regarding the relationship between the two system levels: While the possibility of change in the educational paradigm is certainly limited by the encompassing cultural and political milieu, meaningful movement toward holistic policy and practice is not hopelessly blocked or frozen - particularly at institutional level, yet it is likely to be constrained. Not least, the effectiveness of such movement is dependent on the prior awareness and understanding of change agents as regards the operative paradigm, and their possession of sufficient imagination, will and agency to move beyond it.

Through my doctoral research (Sterling, 2003), I first developed a hierarchical thought model depicting what I termed "systemic levels of knowing" based on a systems view of thought (Bohm, 1992). This suggests a number of layered levels of human knowing, whereby foundational levels shape and inform more immediate and everyday levels (upward arrow - see Figure 2). Conversely, a weaker relationship may be assumed whereby 


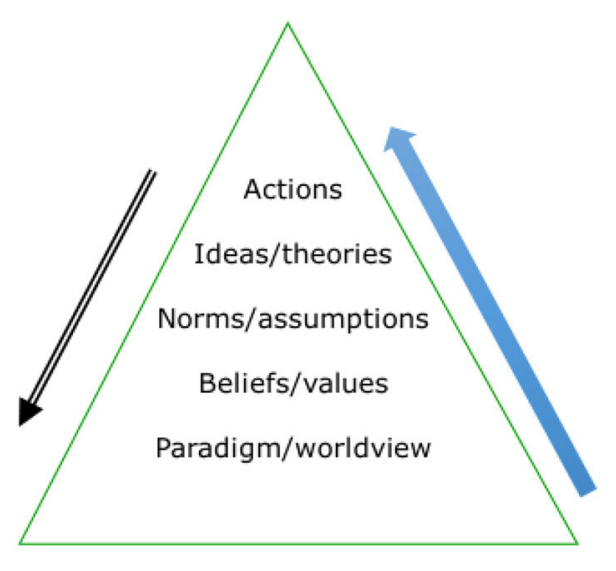

Professor Stephen Sterling University of Plymouth

FIGURE 2 | Levels of knowing (Sterling, 2013).

experience in the world can partially affect foundational levels of perception and knowing (downward arrow). This "downward" affect, however, can at times be strong, for example, through transformational experience which radically revises worldview.

The model provides a simple map that invites the exercise of critical reflexivity - a quality that is key to transformative learning and action. With this model in mind, greater consciousness of how deeper perceptions and conceptions can inform everyday thoughts and actions may be developed. Further, it invites clear reflection on the nature and possibility of alternatives at this foundational level, and the validity of philosophic bases and assumptions that accompany and legitimate such alternatives.

Assuming its validity, the model appears applicable to each person, but also to institutions and entire societies which share any prevailing worldview. A critical point is that, while we are operating in the world of everyday experience, decisions and actions (top of diagram), we are not always aware of deeper levels of perception, assumptions, values and concepts that affect our mindset and behaviors (whether at individual or at group scale).

There is no simple determinism at work here: it is well-known that we sometimes take actions that belie our deeper values, nevertheless there is an overall logical pattern of norms operating between the levels, which form a coherent whole. That is, the whole framework may be seen as an operational paradigm. A second key point is that diversity and difference of interpretation at the more immediate or upper level of knowing (for example in different academic disciplines) can disguise the fact that the underlying worldview may be widely shared. In educational terms, a quote by Lawton (1989) is illustrative:

Every statement that a teacher makes in a classroom is valueladen, connected with ideas about the purpose of education, probably connected with more general values and beliefs, and maybe with the purpose of life. So it is with educational planners and curriculum developers, whether they realize it or not.

A third key point is that, whether the subject is an individual, or group or institution, significant change is easier and more

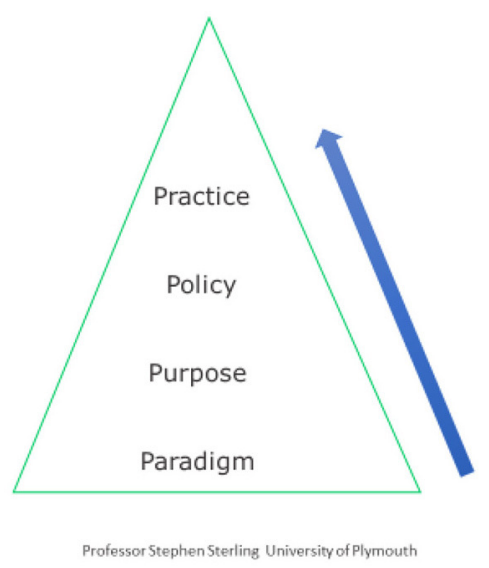

FIGURE 3 | Organizational and educational culture: levels of manifestation (Sterling, 2013).

likely at immediate and practical levels rather than at deeper levels of knowing. Put simply, a strong challenge to how we see the world - the worldview - is a challenge to beliefs, identity, and sense of reality and is therefore likely to be resisted. This helps explain why educational systems and universities are resilient systems, why the response to the sustainability agenda tends to be superficial and partial, and why the profound significance of the sustainability agenda is so often not fully comprehended, or misunderstood.

If we then interpret and overlay the systems "Levels of knowing" framework in terms of educational systems, the following model is suggested, which (in English at least) reflects four nesting "P"s - Paradigm, Purpose, Policy, and Practice (Figure 3). This layered relationship is not directly causal or simple, but again, we can suggest an overall pattern whereby deeper levels of educational culture influence conception and action at more immediate levels.

The deep significance of this layering is that the operative shared paradigm - its embedded assumptions, beliefs and values - shapes, influences and limits debate and practice. It molds the culture of debate and practice as regards what are seen as norms, and conversely, what is seen as marginal, unimportant or irrelevant. The paradigm has added potency where it is unconsciously held or unexamined, and I believe this is often the case institutionally, and amongst individual actors within higher education. As Chapman argues (2002):

Most people are not aware of how they think. This is not because they are unintelligent, it is because their mode of thinking has evolved over many years, has served them well and does not need to be examined or questioned.

Attention in education is usually concentrated on the upper levels of manifestation - policy, research, curriculum and pedagogy, whilst purpose is often assumed or seen as self-evident, and paradigm unexamined and ignored. In other words, most institutions operate within a culture of what Gregory Bateson 
(1972) called Learning 1, or first order learning where policy and practice operates within a given and largely unexamined set of parameters, assumptions and values (Glasser and Hirsch, 2016).

These models help illustrate the challenge of "transformation" as currently advocated by UNESCO and others. Following Meadows's (1999) theory of paradigm change, if we can reevaluate and re-think the foundational paradigm, then it follows that Purpose, Policy and Practice in higher education - and perhaps across any individual institution - will be affected toward a more ecological orientation. The next section elaborates and further explains the Triang Model as a tool for helping this process.

\section{CONCERN, CONCEPTION, AND CONSEQUENCE}

This triadic model attempts to distill out - from the complexity and "mess" of organizational change - three paradigmatic dimensions or components that can act both as lenses on current patterns, and as navigational signposts to alternatives. It is offered to help stimulate thought and reflection.

It important to note that these three dimensions are interrelated and mutually affecting (see Figure 1).

\section{CONCERN}

This is the "Seeing Domain." It relates to Perception and perceptual boundaries, and at individual level subsumes the affective and feeling dimension. In terms of the institution, it applies to how a university sees itself and in relation to the world and planet. It subsumes the institution's ethos and dominant assumptions, its culture, its sense of purpose, what it "stands for," and what it values. In systems terms, this is the institution's "system of concern" or "system of interest," or "horizon of attention" (Bell and Morse, 2003). It is important to note that the system of concern is evidenced by what a university actually does, as opposed to what it says its purpose is - a critical distinction made by the systems theorist Stafford Beer (see https://en.wikipedia.org/wiki/The_purpose_ of_a_system_is_what_it_does).

Ironically, despite the expansionist globalization and the internationalization agenda in higher education in recent years, the system of concern for many universities has become narrowly drawn and strikingly similar worldwide. Concerned primarily with income, financial sustainability, status and positioning, ranking and reputation in a competitive market, most institutions have - for some years - lost "the capacity to engage in critical reflection and advance ways of thinking and acting that go beyond their immediate mandates" (Escrigas, 2016). Further, she writes, universities need to "learn to read reality," and "understand the wider impacts of their actions and the costs of what they are not doing at a time when societal transition is urgently needed."

The common system of concern has suffered from a narrowing that has been considerably aggravated by the utilitarian effects of the marketization and commodification of the sector. Further, the notion of higher education as a public and common good has been eroded, whilst the ethical norms of the university have become subsumed in serving the economy and growth (UNESCO, 2015).

The challenge here is to go the other way - an ethicallyoriented extension of vision, involving conscious re-purposing, and expanding the system of concern to take full account of context: of the current precarious state of the world, of planetary limits (Rockström, 2009) of future scenarios, prospects and possibilities, and questioning deeply the role and responsibility of the university, and of each of its subsystems, in relation to securing socio-ecological well-being into the future as far as this is possible. Escrigas (2016) remarks, "an expanded perspective provides space to consider additional ways to understand reality and to generate innovative solutions to persistent problems," as well as "embrace a way of connecting different types of knowledge, acknowledging their existence and giving them equal value."

\section{CONCEPTION}

This is the "Knowing Domain" and at individual level is the cognitive dimension. In terms of the institution, it relates to overall pattern: how things are conceived, manifested and organized. It covers how knowledge is regarded, and therefore not only embraces the organization of research and curriculum, but how universities are structured (such as separate disciplines and departments), campus management, and governance.

In this domain, the mechanistic and reductionist legacy of the Western intellectual tradition still holds sway, overlain and reinforced in the last few decades by New Public Management control models, commodification, neo-liberal conceptions of useful (marketable) knowledge, and, more recently, the increasing power global EdTech (Williamson and Hogan, 2020).

The challenge here is changing the pattern: toward connection - or re-connection - dismantling (or at least eroding) the barriers, silos and compartmentalisation, and instead: building distributed leadership; a participative and transparent collective culture; inclusivity and cross-institutional collegiality; co-inquiry and inter- and trans-disciplinarity; valuing the arts and humanities in association with sciences; affective, cognitive and conative learning being seen as complementary and of equal value; and facilitating emergence and positive synergies through ensuring as far as possible that the university is dynamic, integrated, coherent yet diverse, highly communicative, fluid, open and permeable in relation to its community and wider environment.

In other words, its structures and view of knowledge should be congruent with real-world complexity and dynamics - the complex socio-ecological systems within which the university is unavoidably embedded as a subsystem, and which it affects and is affected by. This includes the multiple systemic wicked problems in which it is unavoidably connected. This call echoes the shift from the pursuit of knowledge toward wisdom that Maxwell (2020) has advocated for many years. 


\section{CONSEQUENCE}

This is the "Doing domain" and relates to Practice. It covers organizational and student learning and pedagogy, research and the work of the university and its effects intended or otherwise on staff, on students, on the community, the wider world, the biosphere and other planetary systems. It relates to the engagement that the university has with its community and environment, its investments, the effects of its research, the values, competencies and skills of its graduates, and the impact of all this on social and ecological systems [which must be seen as inextricably linked (Olsson et al., 2017)].

The challenge here is re-orientation and integration within planetary boundaries. The urgent global need now is one of restoration and regeneration of natural systems, local economies, communities, and civic life. Universities need to ensure their net effect or impact is supportive of this movement, is regenerative and builds positive synergies consistent with developing sustainable systems, through participatory and exploratory pedagogies, and engaged real-world research. Contemporary conditions of uncertainty, complexity, threat and the blurring of boundaries require a fundamental shift from narrowly-drawn purposes and indicators of success, control, the illusion of certainty and predictability, standardization, delivery and topdown intervention toward engaged participation, and a coevolutionary relationship with society marked by openness to diversity, process and the embrace of emergence and change in the cause of human and ecological well-being.

The three interrelated shifts envisioned here are implied by - and also manifest - an ecological/relational paradigm or worldview based on an extended epistemology, on participative knowing and social inquiry, on and real-world engagement (Reason and Bradbury, 2001; Bawden, 2006).

\section{RE-THINKING HIGHER EDUCATION}

Universities have unrivaled capacity to shape the values, knowledge, skills and research that are crucial to a society in transition to a low carbon and safe future, and many are making critically important contributions toward this end.

Yet the net effect of higher education is still negative, resulting from decades marked by narrowly drawn systems of interest (Concern), siloed and hierarchical structures, and fragmented view of knowledge (Conception), and a limited view of what the impact of a university, and of its graduates, should and can be (Consequence). Because these three dimensions reflect the three constituents of paradigm, there is an internal logical consistency between them as regards the ways that universities see themselves and currently operate. Current international concern to transform education (UNESCO, 2016; ICFE, 2021) requires envisioning and articulating an alternative paradigm which is also logically consistent, is achievable and has net benefit to socio-ecological wellbeing. My work has attempted to make the case for, and elucidate, an ecological/systemic paradigm which can inspire system re-design and thereby inform educational thinking, purpose, policymaking and practice.
Using the Triang model - and maintaining a high level of abstraction and few keywords - we can suggest the need for a paradigm movement in higher education from the dominant paradigm toward an ecological (relational) framework as follows, through the conscious practice of institutional critical reflexivity and organizational learning (Table 2):

Quite clearly, this model is conceived at a very high level of abstraction, but with the metaphor of "roadmap" in common currency, it offers a broad navigational tool to help determine and evaluate the direction of travel from mechanism/reductionism toward systemisism/holism. I fully recognize that this is not a simple or one-off journey but rather will involve partial movement over time. The feedback loop to the left of the diagram indicates this will often be a cyclical process.

The key to traversing this roadmap sufficiently and effectively is systemic learning - by individuals, institutions and communities - through inclusivity and collaboration together with a measure of humility and willingness to learn. This is challenging and difficult territory - progress depending on, "creating a kind of temporary psychological safety in order for people to do the necessary work of unlearning, crossing scales, confronting diversity, and acknowledging positive and negative dynamics, but it also relies on making people uncomfortable enough to prepare them to move through these contested, unknowable systems with courage, resilience, and grace" (Moore et al., 2018).

In the context of multiple and pressing global crises, the necessary response by universities is to move toward becoming critical learning systems (Bawden, 1997, 2006) as their prime raison d'etre and modus operandi. This beckons a way of being that would revolutionize research, teaching and learning, and community engagement as "an enduring, ever-unfolding and enfolding process of experiential learning" in the pursuit of a liveable future (Bawden, 2006).

As I have recently argued (Sterling, 2021):

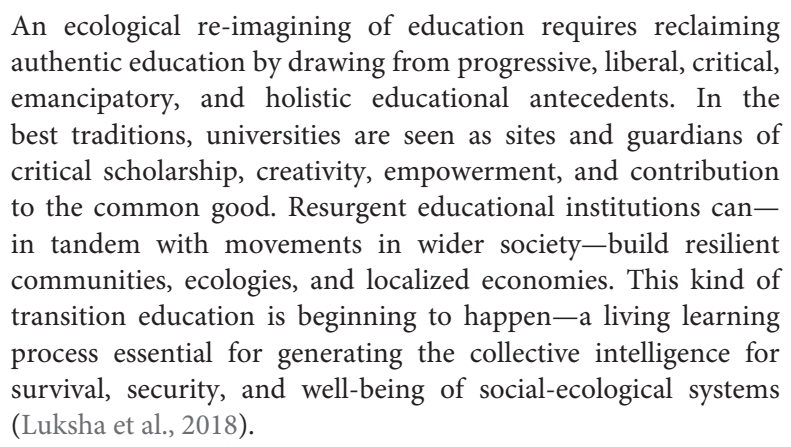

There are emerging signs in some parts of the sector of a willingness and energy to re-think policy and practice. Beyond whole institutional strategies reflected in a small but increasing number of universities internationally, there is growing interest in "critical engagement" and the civic role of institutions driven by committed staffs and students in both research and teaching (Facer, 2021), and growing examples of innovative projects sprouting within institutions which allow facilitative 
TABLE 2 | The university - moving toward an ecological paradigm.

\begin{tabular}{|c|c|c|}
\hline \multicolumn{3}{|l|}{ A MOVEMENT FROM: } \\
\hline CONCERN - mechanistic & CONCEPTION- reductionist & $\begin{array}{l}\text { CONSEQUENCE - individualist } \\
\text { (the institution, the graduate) }\end{array}$ \\
\hline \multicolumn{3}{|l|}{ REQUIRES } \\
\hline $\begin{array}{l}\text { EXPANSION - towards an } \\
\text { ecological system of } \\
\text { Concern }\end{array}$ & $\begin{array}{l}\text { CONNECTION - toward holistic } \\
\text { Conception }\end{array}$ & $\begin{array}{l}\text { INTEGRATION - towards social } \\
\text { and ecological wellbeing as } \\
\text { Consequence }\end{array}$ \\
\hline \multicolumn{3}{|l|}{ THROUGH } \\
\hline RE-PURPOSING & RE-THINKING & RE-ORIENTATION \\
\hline \multicolumn{3}{|c|}{ IN ORDER TO SIGNIFICANTLY IMPROVE } \\
\hline $\begin{array}{l}\text { AWARENESS = greater } \\
\text { Responsibility in HE }\end{array}$ & $\begin{array}{l}\text { ALIGNMENT = greater real } \\
\text { world Congruence in HE }\end{array}$ & $\begin{array}{l}\text { AFFECT = greater } \\
\text { Response-ability in } \mathrm{HE}\end{array}$ \\
\hline
\end{tabular}

space (see "Practices" at https://greattransition.org/gti-forum/ pedagogy-transition).

These movements are evidenced by greater recognition of the need to educate for thriving and resilient socio-ecological systems, involving such approaches as anticipative education, service learning in the community, action research, participative and experiential pedagogies, co-creative and cooperative inquiry, transdisciplinary and interdisciplinary engagement, the nurturing of sustainability competencies, an open-ended and provisional approach to knowledge, valuing the arts, a valuing of place, futures work and the proper embrace of multiple perspectives including alternative, non-Western knowledge traditions and hitherto marginalized voices.

The future is unknown and cannot be taught, but must be consciously made, which is why higher education needs to be creative, explorative, experiential, innovative, and always critically reflexive. It is about growing and manifesting a collective culture of critical commitment. Clearly, this is necessarily both inner work - a shift toward participative consciousness and responsibility - and outer work, a shift of culture toward collaboration and regeneration.

Whilst progress is inevitably uneven, increasing numbers of international academic networks and initiatives reflect sustainability concerns and priorities. Further, interest is growing rapidly in supporting regenerative sustainability which goes beyond harm reduction (moving from "doing less badly") toward actions that improve human well-being in harmony with restoring natural systems (Luksha et al., 2018; Facer, 2021; Robinson, 2021). This emergence of "regenerative education" may be seen as part of a wider movement now asserting, articulating and practicing a regenerative culture of restoration and renewal across many aspects of human activity (Wahl, 2017, see https://www.thefuturescentre.org/wp-content/uploads/2020/ 11/Future-of-Sustainability-2020_Time-to-transform.pdf).

Small and independent institutions such as Schumacher College in Devon, UK, are playing a key role in this work (Luksha et al., 2018; Sterling et al., 2018, and see https://ecoversities. org/; https://campus-transition.org/en/our-project/ and https:// gaiauniversity.org/) but there are increasing exemplars arising in the mainstream (see https://www.eauc.org.uk/global_alliance). Whether these kinds of shifts are sufficiently widespread, systemically embedded and deeply rooted to catalyze the wholesale shift now urgently needed cannot yet be known. But it augurs well and aligns higher education to the wider social learning and cultural shift which, while incipient, now appears to be taking effect globally.

\section{CONCLUSION}

An explosion of awareness of the great issues of our time in the last few years, spurred by accelerating evidence of ecological degeneration, economic instability and social upheaval, has led to a growing critique of "business as usual" 
as a prime causative factor, and to consequent calls for the "transformation" of established practices across many sectors. Education policy and practice is no exception in this call, which is increasingly affecting the mainstream. Universities are called upon to re-think, and re-design, their Concern (purpose), Conception (operation) and Consequence (impact) based upon a systemic or ecological/relational learning paradigm, if they are to make the substantial positive difference to the chances of global survival and well-being that they are uniquely capable of. Thereby lies hope, but are sufficient universities worldwide reading the signs of the times sufficiently?

\section{REFERENCES}

Armon, J., Scoffham, S., and Armon, C. (2019). Prioritizing Sustainability Education - A Comprehensive Approach. Abingdon: Routledge. doi: 10.4324/9780429021800

Assadourian, E. (2017). Rethinking Education on a Changing Planet, Chapter 1, EarthEd: Rethinking Education on a Changing Planet. Washington, DC: WorldWatch Institute. doi: 10.5822/978-1-61091-843-5_1

Banathy, B. (1991). Systems Design of Education. New Jersey, NJ: Educational Technology Publications.

Bateson, G. (1972). Steps to an Ecology of Mind. San Francisco, CA: Chandler.

Bateson, G. (1980). Mind and Nature - A Necessary Unity. New York, NY: Bantam Books.

Bateson, G., and Bateson, C. (1988). Angels Fear - Towards an Epistemology of the Sacred. New York, NY: Bantam Books.

Bawden, R. (1997). "Leadership for Systemic Development" in Centre for Systemic Development, Resource Manual for Leadership and Change. Hawkesbury: University of Western Sydney.

Bawden, R. (2006). "Critical engagement, transformation, and development," in Coming to Critical Engagement, eds F. Fear, C. Rosaen, R. Bawden, and P. Foster-Fishman (Lanham, MD: University Press of America).

Bawden, R. J. (1987). "Learning systems for technological change," in Proceedings Centenary International Conference - Technology, Education and Society-Future Directions (Melbourne: RMIT).

Bawden, R. J., and Allenby, B. (2017). Sustainability Science and the Epistemic Challenge: Some matters philosophical and why we ought to come to know them better. Sustainability Sci. 12, 901-905. doi: 10.1007/s11625-017-0480-y

Bell, S., and Morse, S. (2003). Measuring Sustainability - Learning from Doing. London: Earthscan.

Bohm, D. (1992). Thought as a System. London: Routledge.

Capra, F., and Luisi, P. L. (2014). The Systems View of Life - a Unifying Vision. Cambridge: Cambridge University Press.

Chapman, J. (2002). System Failure. London: Demos.

Cook, J. W. (2019). Sustainability, Human Well-Being, and the Future of Education. Cham: Palgrave.

Cortese, A. D. (2003). The critical role of higher education in creating a sustainable future. Plan. Higher Educ. 31, 15-22.

Costanza, R., Kubiszewski, I., Pickett, K., Trebeck, K., De Vogli, R., Ragnarsdóttir, K., et al. (2020). Club of Rome, After the Crisis: Two Possible Futures. Available online at: https://www.clubofrome.org/blog-post/after-the-crisistwo-possible-futures-2/ (accessed September 22, 2021).

Cunliffe, A. (2016). On becoming a critically reflexive practitioner: What does it mean to be reflexive? J. Manage. Educ. 40, 740-746. doi: $10.1177 / 1052562916668919$

Dash, A. (2019). "Good anthropocene: The zeitgeist of the 21st century," in Transition Strategies for Sustainable Community Systems - Design and Systems Perspectives, ed A. K. R. Nayak (London: Springer). doi: 10.1007/978-3-030-00356-2_2

Elgin, D. (1994). "Building a sustainable species-civilisation - a challenge of culture and consciousness," in Futures, Special Issue, Visions of Sustainability, eds

\section{DATA AVAILABILITY STATEMENT}

The original contributions presented in the study are included in the article/supplementary material, further inquiries can be directed to the corresponding author.

\section{AUTHOR CONTRIBUTIONS}

The author confirms being the sole contributor of this work and has approved it for publication.

D. McKenzie-Mohr and M. Marien (California, CA: Cambridge Millennium Project). doi: 10.1016/0016-3287(94)90100-7

Escrigas, C. (2016). A Higher Calling for Higher Education. Boston, MA: Tellus Institute.

Facer, K. (2021). Beyond Business as Usual: Higher Education in the Era of Climate Change, Debate Paper 24, Oxford: Higher Education Policy Institute (HEPI).

Fear, F., Rosaen, C., Bawden, R., and Foster-Fishman, P. (2006). Coming to Critical Engagement. Lanham, MD: University Press of America.

Figueres, C., and Carnac, T. (2020). The Future We Choose-Surviving the Climate Crisis. London: Manilla Press.

Glasser, H., and Hirsch, J. (2016). Towards the development of robust sustainability competences. Sustainab. J. Record 9, 121-134. doi: 10.1089/SUS.2016.29054.hg

Homer-Dixon, T. (2006). The Upside of Down - Catastrophe, Creativity and the Renewal of Civilisation. London: Souvenir Press.

ICFE (2021). Futures of Education - Learning to Become, International Commission on the Futures of Education. Available online at: https://unesdoc.unesco.org/ ark:/48223/pf0000375746/

Ison, R., and Russell, D. (2000). Agricultural Extension and Rural Development Breaking Out of Traditions, a Second-Order Systems Perspective. Cambridge, CA: Cambridge University Press.

Jacobs, J. (2005). Dark Age Ahead. Toronto, ON: Vintage Canada.

Lange, E. A., O’Neil, J. K. P., and Ross, K. (2021). Educating during the great transformation: relationality and transformative sustainability education. Stud. Adult Educ. Learn. 27, 23-46. doi: 10.4312/as/9692

Laszlo, A. (2019). Education for the future: The emerging paradigm of thrivable education. World Futures. 3, 174-183. doi: 10.1080/02604027.2018.1463760

Laszlo, E. (1989). The Inner Limits of Mankind. London: One World.

Lautensach, A. K. (2020). Survival How? Education, Crisis, Diachronicity and the Transition to a Sustainable Future. Paderborn: Schoeningh-Brill. doi: 10.30965/9783657702879

Lawton, D. (1989). Education, Culture and the National Curriculum. London: Hodder and Stoughton.

Luksha, P., Cubista, J., Laszlo, A., Popovich, M., and Ninenko, I. (2018). Educational Ecosystems for Societal Transformation, Global Education Futures. Available online at: https://drive.google.com/file/d/ 1zmxNZpeitzDgQ7hVtj1u0FCm3EsXKk-t/view (accessed July 20, 2021).

Martin, S., and Sterling, S. (2019). On track for a sustainable future? Int. Assoc. Universities. 24:2. Available online at: https://www.iau-aiu.net/IMG/pdf/iau_ horizons_vol.24.2_light.pdf

Maturana, H., and Varela, F. (1987). The Tree of Knowledge: the Biological Roots of Human Understanding. Boston, MA: Shambala Press.

Maxwell, N. (2020). Our Fundamental Problem: A Revolutionary Approach to Philosophy. Montreal, QC: McGill-Queens University Press. doi: 10.2307/j.ctv1131gtt

McGilchrist, I. (2009). The Master and His Emissary: The Divided Brain and the Making of the Western World. New Haven, CT: Yale University Press.

Meadows, D. H. (1999). Leverage points: places to intervene in a system, the donella meadows project. Acad. Syst. Change. Available online at: https:// donellameadows.org/archives/leverage-points-places- to-intervene-in-asystem/ 
Meadows, D. H., Meadows, D. L., and Randers, J. (1992). Beyond the Limits - Global Collapse or a Sustainable Future. London: Earthscan.

Milbrath, L. (1994). "Stumbling blocks to a sustainable society" in Futures, Special Issue, Visions of Sustainability, eds D. McKenzie-Mohr and M. Marien (Cambridge). doi: 10.1016/0016-3287(94)90101-5

Moore, M. L., Olsson, P., Nilsson, W., Rose, L., and Westley, F. R. (2018). Navigating emergence and system reflexivity as key transformative capacities: experiences from a Global Fellowship program. Ecol. Soc. 23:38. doi: 10.5751/ES-10166-230238

Norgaard, R. (1994). Development Betrayed - The End of Progress and a CoEvolutionary Revisioning of the Future. London: Routledge.

Olsson, P., Moore, M. L., Westley, F. R., and McCarthy, D. D. P. (2017). The concept of the Anthropocene as a game-changer: a new context for social innovation and transformations to sustainability. Ecol. Soc. 22:31. doi: 10.5751/ES-09310-220231

Orr, D. (2016). Dangerous Years - Climate Change, the Long Emergency and the Way Forward. New Haven, CT: Yale University Press.

Orr, D. (2021). A New Agenda for Higher Education, Great Transition Initiative (GTI). Available online at: https://greattransition.org/gti-forum/pedagogytransition-orr (accessed May 5, 2021).

Peters, G. (1999). "A systems failures view of the UK national commission into higher education report," in Systems Research and Behavioral Science, ed R. Ison (John Wiley).

Reason, P., and Bradbury, H. (2001). Handbook of Action Research - Participative Practice and Enquiry. London: Sage Publications.

Robinson, J. (2021). Fostering Sustainability Leaders, Great Transition Initiative (GTI). Available online at: https://greattransition.org/gti-forum/pedagogytransition-robinson (accessed May 5, 2021).

Rockström, J. (2009). A safe operating space for humanity. Nature 461, 472-475. doi: $10.1038 / 461472 \mathrm{a}$

Silova, I., Komatsu, H., and Rappleye, J. (2018). Facing the Climate Change Catastrophe: Education as Solution or Cause? Available online at: https://www. norrag.org/facing-the-climate-change-catastrophe- education-as-solutionor-cause-by-iveta-silova-hikaru-komatsu-and-jeremy-rappleye/ (accessed February 5, 2021).

Smith, W. (2016). The Global Testing Culture - Shaping Education Policy, Perceptions, and Perceptions, and Practice. Oxford: Symposium Books. doi: $10.15730 /$ books.94

Smitsman, A., Martens, P., and Laszlo, A. (2019). The polarization effect - healing our worldviews. Systema 7, 1-23.

Sterling, S. (2001). Sustainable Education - Re-visioning Learning and Change, Schumacher Briefing no6. Dartington: Schumacher Society/Green Books.

Sterling, S. (2003). Whole Systems Thinking as a Basis for Paradigm Change in Education: Explorations in the Context of Sustainability. PhD diss., Centre for Research in Education and the Environment, University of Bath.

Sterling, S. (2004). "Higher education, sustainability and the role of systemic learning," in Higher Education and the Challenge of Sustainability: Contestation, Critique, Practice, and Promise, eds P. B. Corcoran and A. E. J. Wals (Dordrecht: Kluwer Academic).

Sterling, S. (2007). "Riding the storm: towards a connective cultural consciousness," in Social Learning Toward a More Sustainable World: Principles, Perspectives, and Praxis, ed A. E. J. Wals (Waginengen: Waginengen Academic Publishers).

Sterling, S. (2009). "Sustainable education," in Science, Society and Sustainability: Education and Empowerment for an Uncertain World, eds D. Gray, L. ColucciGray, and E. Camino (New York, NY: Routledge).

Sterling, S. (2012). The Future Fit Framework - An Introductory Guide to Teaching and Learning for Sustainability in HE. New York, NY: The Higher Education Academy.

Sterling, S. (2013). “The sustainable university - challenge and response," in The Sustainable University - Progress and Prospects, eds S. Sterling, L. Maxey, and H.
Luna (Abingdon: Routledge/Earthscan). doi: 10.4324/9780203101780

Sterling, S. (2017). "Assuming the future - re-purposing education in a volatile age," in Post-Sustainability and Environmental Education: Remaking Education for the Future, eds Sterling, S. and Jickling, B (London: Pivot Press/Palgrave).

Sterling, S. (2021). "Educating for the Future We Want", Opening Essay for GTI Discussion Forum The Pedagogy of Transition. Boston, MA: Great Transition Initiative (GTI).

Sterling, S., Dawson, J., and Warwick, P. (2018). Transforming sustainability education at the creative edge of the mainstream - a case study of schumacher college. J. Transform. Educ. 16:3.

Sterling, S., and Martin, S. (2019). Climate Crisis and the Response-ability of Universities, Times Higher Education. Available online at: https:// www.timeshighereducation.com/blog/climate-crisis-and-response-abilityuniversities (accessed November 16, 2019).

UNESCO (2015). Rethinking Education - Towards a Global Common Good? Paris: UNESCO.

UNESCO (2016). Education for People and Planet - 'Creating Sustainable Futures for All', Global Education Monitoring (GEM). Paris: UNESCO.

UNESCO (2020). Education for Sustainable Development - Roadmap: ESD for 2030. Paris: UNESCO.

Wahl, D. (2017). Sustainability is Not Enough: We Need Regenerative Cultures. Available online at: https://designforsustainability.medium.com/sustainabilityis-not-enough-we-need-regenerative-cultures- $4 \mathrm{abb} 3 \mathrm{c} 78 \mathrm{e} 68 \mathrm{~b} \quad$ (accessed September 22, 2021).

Wals, W. (2021). The Power of Transgressive Learning. Great Transition Initiative (GTI). Available online at: https://greattransition.org/gti-forum/pedagogytransition-wals (accessed May 6, 2021).

Weyhenmeyer, G., and Steffen, W. (2020). A Warning on Climate and the Risk of Societal Collapse. Available online at: https://www.theguardian.com/ environment/2020/dec/06/a-warning-on-climate-and-the-risk-of-societalcollapse (accessed February 16, 2021).

Wilber, K. (1996). A Brief History of Everything. Dublin: Gill and Macmillan.

Williamson, B., and Hogan, A. (2020). Commercialisation and Privatisation in/of Education in the Context of Covid-19. Brussels: Education International Research.

Wright, D., and Hill, S. (2021). Transforming Worldviews \& Practices: Social Ecology and Education. Abingdon: Routledge. doi: 10.4324/9781003033462

Wulf, A. (2020). Grading Goal Four: Tensions, Threats, and Opportunities in the Sustainable Development Goal on Quality Education. Leiden: Brill Sense. doi: $10.1163 / 9789004430365$

Zweers, W. (2000). Participation With Nature - Outline for an Ecologisation of Our Worldview. Utrecht: International Books.

Conflict of Interest: The author declares that the research was conducted in the absence of any commercial or financial relationships that could be construed as a potential conflict of interest.

Publisher's Note: All claims expressed in this article are solely those of the authors and do not necessarily represent those of their affiliated organizations, or those of the publisher, the editors and the reviewers. Any product that may be evaluated in this article, or claim that may be made by its manufacturer, is not guaranteed or endorsed by the publisher.

Copyright $(02021$ Sterling. This is an open-access article distributed under the terms of the Creative Commons Attribution License (CC BY). The use, distribution or reproduction in other forums is permitted, provided the original author(s) and the copyright owner(s) are credited and that the original publication in this journal is cited, in accordance with accepted academic practice. No use, distribution or reproduction is permitted which does not comply with these terms. 